Provided for non-commercial research and educational use only. Not for reproduction or distribution or commercial use.

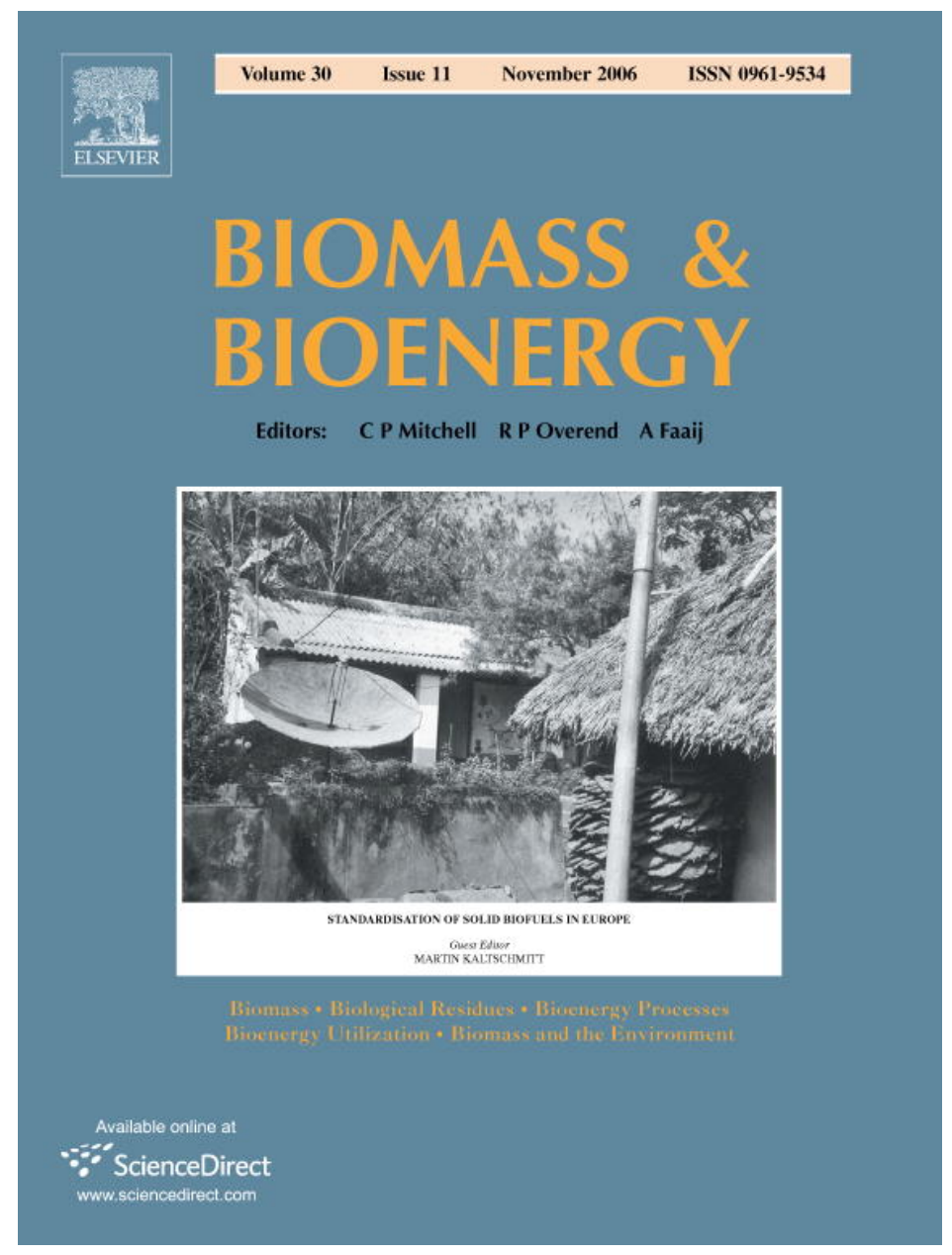

This article was originally published in a journal published by Elsevier, and the attached copy is provided by Elsevier for the author's benefit and for the benefit of the author's institution, for non-commercial research and educational use including without limitation use in instruction at your institution, sending it to specific colleagues that you know, and providing a copy to your institution's administrator.

All other uses, reproduction and distribution, including without limitation commercial reprints, selling or licensing copies or access,

or posting on open internet sites, your personal or institution's website or repository, are prohibited. For exceptions, permission may be sought for such use through Elsevier's permissions site at: 


\title{
Comparative study of durability test methods for pellets and briquettes
}

\author{
Michaël Temmerman $^{\mathrm{a}, *}$, Fabienne Rabier ${ }^{\mathrm{a}}$, Peter Daugbjerg Jensen ${ }^{\mathrm{b}}$, \\ Hans Hartmann ${ }^{\mathrm{c}}$, Thorsten Böhm ${ }^{\mathrm{c}}$ \\ ${ }^{\mathrm{a} C e n t r e}$ wallon de Recherches agronomiques (CRA-W), 146, chaussée de Namur, B-5030, Gembloux, Belgium \\ ${ }^{\mathrm{b}}$ Forest \& Landscape, The Royal Veterinary and Agricultural University, Rolighedsvej 23, DK-1958 Frederiksberg C, Denmark \\ ${ }^{\mathrm{c}}$ Technologie- und Förderzentrum für Nachwachsende Rohstoffe-TFZ, Schulgasse 18, D-94315 Straubing, Germany
}

Received 17 November 2005; accepted 9 June 2006

Available online 30 August 2006

\begin{abstract}
Different methods for the determination of the mechanical durability (DU) of pellets and briquettes were compared by international round robin tests including different laboratories. The DUs of five briquette and 26 pellet types were determined. For briquettes, different rotation numbers of a prototype tumbler and a calculated DU index are compared. For pellets testing, the study compares two standard methods, a tumbling device according to ASAE S 269.4, the Lignotester according to ÖNORM M 7135 and a second tumbling method with a prototype tumbler. For the tested methods, the repeatability, the reproducibility and the required minimum number of replications to achieve given accuracy levels were calculated. Additionally, this study evaluates the relation between DU and particle density.

The results show for both pellets and briquettes, that the measured DU values and their variability are influenced by the applied method. Moreover, the variability of the results depend on the biofuel itself. For briquettes of DU above $90 \%$, five replications lead to an accuracy of $2 \%$, while 39 replications are needed to achieve an accuracy of $10 \%$, when briquettes of DU below $90 \%$ are tested. For pellets, the tumbling device described by the ASAE standard allows to reach acceptable accuracy levels $(1 \%)$ with a limited number of replications. Finally, for the tested pellets and briquettes no relation between DU and particle density was found.
\end{abstract}

(C) 2006 Elsevier Ltd. All rights reserved.

Keywords: Pellets; Briquettes; Durability; Biofuel quality; Lignotester; Particle density

\section{Introduction}

Durability (DU) and particle density are the main parameters describing the physical quality of densified solid biofuels like pellets and briquettes. Both fuel types are susceptible to mechanical wear, which leads to production of fine particles or dust during transport, transhipment and storage. Dust emissions are not only an inconvenience for the consumer, they are also a health hazard [1]. Additionally, fine particles and dust can disturb feeding systems of boilers and may lead to inhomogeneous combustion processes. Finally, dust may contribute to fire and explosion risks during handling, storage and transhipment [2].

\footnotetext{
${ }^{*}$ Corresponding author. Fax: + 3281615847 .

E-mail address: temmerman@cra.wallonie.be (M. Temmerman).
}

Mechanical DU is a quality parameter that is defined as the ability of densified biofuels to remain intact when handled [3]. It is measured by the resistance of densified fuels towards shock or/and friction. Therefore, DU is an important quality parameter with regard to handling and transportation processes of briquettes and pellets. Particle density is another parameter, which is commonly taken as a measure of DU, e.g. high particle density leads to a high DU. However, as shown by Obenberger and Thek [4], this assumption is not valid.

The presented research, realised within the European project BioNorm, aims at providing a knowledge basis to the Technical Committee TC335 at CEN ("Standards for solid biofuels"). Its main goal is therefore to identify and to evaluate the best appropriate methods for the DU determination of pellets and briquettes. Already described methods and existing national standards serve as basis. 


\section{Material and method}

\subsection{Sample material}

The briquettes selected for the round robin trials are made from wood and are commercially available in their country of origin. The briquette selection includes two briquette types produced by extruder press (B1, B2), one was produced by a chamber press (B3) and two by piston presses (B4, B5) (Table 1). As high moisture contents (MC) may influence the DU result [5], this parameter was measured prior to the determinations in order to avoid fuel moisture contents of more than $10 \%$.

The briquettes used in the samples were prepared by cutting at both ends to a length equivalent to two times the diameter. Depending on the laboratory, the cutting was performed by blade or band saw.
The DUs of two pellet selections (Table 2), were determined during these presented trials. The first selection included wood pellets (6 and $8 \mathrm{~mm}$ diameter) and agricultural residues pellets (straw, hay and Miscanthus) produced in Austria, Denmark, Germany and Spain. The second selection included 10 wood and one straw pellets, all commercially available in their country of origin (Austria, Belgium, Denmark, Finland and Germany). The first pellets selection was used for method and fuel comparisons, while the second one was applied for a round robin test designed for comparing the results of the method described by ASAE S269.4 (Tumbler) and ÖNORM M 7135 (Pneumatic).

The moisture contents of the pellet samples were determined before testing. As shown by Obernberger and Thek [4], MC and DU are not correlated at moisture content levels below $10 \%$. Only pellets with moisture

Table 1

Description of the selected briquettes for the round robin trials

\begin{tabular}{|c|c|c|c|c|}
\hline Briquette code & Press type & Shape & Raw material & Country of origin \\
\hline B1 & Extruder & & Mixed wood & Belgium \\
\hline B2 & Extruder & & Hardwood & Germany \\
\hline B3 & Chamber & & Mixed wood & Germany \\
\hline B4 & Piston & & Mixed wood & Spain \\
\hline B5 & Piston & & Softwood & Austria \\
\hline
\end{tabular}

Table 2

Description of the selected pellets

\begin{tabular}{|c|c|c|c|c|c|c|c|}
\hline \multicolumn{4}{|c|}{ Pellets selection 1} & \multicolumn{4}{|c|}{ Pellets selection 2} \\
\hline Pellets code & Diameter $(\mathrm{mm})$ & Raw material & Country of origin & Pellets code & Diameter (mm) & Raw material & Country of origin \\
\hline $\mathrm{P} 1$ & 6 & Mixed wood & Belgium & P16 & 6 & Mixed wood & Belgium \\
\hline $\mathrm{P} 2$ & 6 & Softwood & Belgium & P17 & 6 & Softwood & Belgium \\
\hline P3 & 6 & Hardwood & Spain & P18 & 8 & Mixed wood & Denmark \\
\hline $\mathrm{P} 4$ & 6 & Hardwood & Spain & P19 & 8 & Mixed wood & Denmark \\
\hline P5 & 8 & Mixed wood & Denmark & $\mathbf{P} 20$ & 6 & Mixed wood & Germany \\
\hline P6 & 8 & Mixed wood & Denmark & $\mathrm{P} 21$ & 10 & Straw & Germany \\
\hline P7 & 8 & Mixed wood & Denmark & $\mathrm{P} 22$ & 6 & Mixed wood & Austria \\
\hline P8 & 6 & Mixed wood & Germany & $\mathrm{P} 23$ & 6 & Mixed wood & Austria \\
\hline P9 & 6 & Mixed wood & Germany & $\mathrm{P} 24$ & 6 & Mixed wood & Austria \\
\hline P10 & 9 & Straw & Germany & $\mathrm{P} 25$ & 6 & Mixed wood & Austria \\
\hline P11 & 6 & Miscanthus & Germany & $\mathrm{P} 26$ & 8 & Spruce & Finland \\
\hline P12 & 6 & Softwood & Austria & & & & \\
\hline P13 & 6 & Softwood & Austria & & & & \\
\hline P14 & 8 & Hay & Austria & & & & \\
\hline P15 & 9 & Straw & Austria & & & & \\
\hline
\end{tabular}


content below $10 \%$ were included in the trials, in order to avoid the MC influencing the DU results.

\subsection{Briquettes $D U$ test}

The briquette DU is estimated by using a dustproof rotating drum prototype (Fig. 1). The drum has an internal diameter and a $598 \mathrm{~mm}$ depth (volume 1681). It is equipped with a baffle $(200 \times 598) \mathrm{mm}$, perpendicular to the wall surface of the cylinder. In the tests, presented here the rotation speed was fixed at $21 \mathrm{rpm}$.

A test portion of 21 sample material, from which fine particles had been removed, was weighed to the nearest $0.1 \mathrm{~g}$ and placed in the drum for 105, 210, 315, 410 and 630 rotations. After each tested rotation number, the sample material was removed from the drum and screened mechanically or manually for $30 \mathrm{~s}$ using a $40 \mathrm{~mm}$ metal wire cloth according to ISO 3310-1 [6]. The particles remaining on the sieve (sieve oversizes) were weighed to the nearest $0.1 \mathrm{~g}$. Both, sieve over- and undersizes were returned into the drum and the tumbling was continued until the subsequent tested rotation number was achieved. Tumbling, sieving and weighing procedures were continued until each sample was exposed to 630 rotations. The DU was calculated from the mass share of the sieve oversizes to the total initial mass. The results are given in percentage as the mean value of five replications.

Based on the DU result obtained for each rotating number, a DU curve was plotted with the number of rotations on the abscissa. From this curve a DU index was defined as the ratio, in percentage, between the area under the DU curve and the area related to a non-abraded material [5].

An international round robin was conducted with five briquette types (Table 1), which were shipped to five European laboratories. For the data analysis, each rotating number and the DU index were considered as separate methods.

\subsection{Pellet DU test}

\subsubsection{Principles}

2.3.1.1. The ASAE drum. The ASAE S 269.4 standard [7] describes a tumbling device (Fig. 2) made of a rectangular

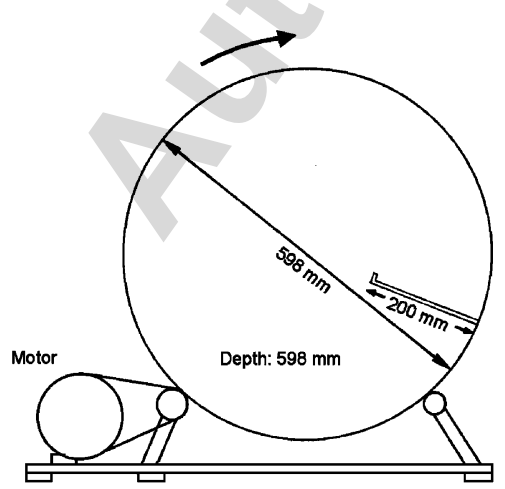

Fig. 1. Principle of the briquette durability tester.

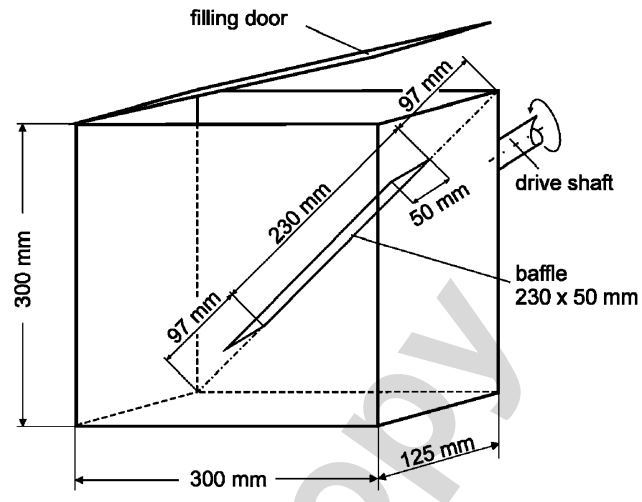

Fig. 2. ASAE S269.4 apparatus for durability testing of pellets.

container in aluminium or stainless steel with inner dimensions of $(300 \times 300 \times 125) \mathrm{mm}$. In order to enforce the tumbling effect the box is equipped with a $230 \mathrm{~mm}$ long baffle, which extends $50 \mathrm{~mm}$ into the container. The baffle is affixed symmetrically to a diagonal of one side of the box. Rivets and screws are kept to a minimum and they are well rounded. The container rotates on an axis, which is centered perpendicular to the sides of the box. The rotation speed is fixed to $50 \mathrm{rpm}$. In the trials described here, a $500 \mathrm{~g}$ sample was tumbled for 500 rotations before being sieved manually with a $3.15 \mathrm{~mm}$ round hole sieve according to ISO 3310.2 [8]. The DU is expressed as the percentage in mass of the pellets remaining on the sieve to the total sample weight. It is calculated as the mean value of three replications.

\subsubsection{The lignotester}

The ÖNORM M 7135 standard [9] refers to a commercial device (Ligno-Tester LT II of Borregaard Lignotech), which exposes the pellets sample to shocks inside a test chamber. The sample material is swirled by a defined air stream that induces the particles to collide against each other and the perforated walls of the test chamber. The test chamber has a four side pyramid form (walls consist of a $2 \mathrm{~mm}$ round hole sieve), which is orientated with the tip downwards (Fig. 3). The inside dimensions of the pyramid are $(230 \pm 5) \mathrm{mm}$ at the base and $(126 \pm 10) \mathrm{mm}$ in height. For the tests described here, the fines were removed, before testing, by sieving the sample manually with a $3.15 \mathrm{~mm}$ round holes sieve [8]. A $(100 \pm 0.1) \mathrm{g}$ sample is placed in the test chamber before an air stream of 70 mbar was blown for $60 \mathrm{~s}$ into the test chamber. During the treatment the abraded fines were collected as sieve undersize below the perforated test chamber. After the device has automatically switched off, the remaining pellets in the test chamber are removed and weighed. The DU is expressed as the percentage in mass of the pellets remaining in the chamber to the initial sample mass. It is calculated as the mean value of five replications.

2.3.2.1. The briquette drum. The procedure and the briquette DU tester are described in Section 2.2. For pellet 


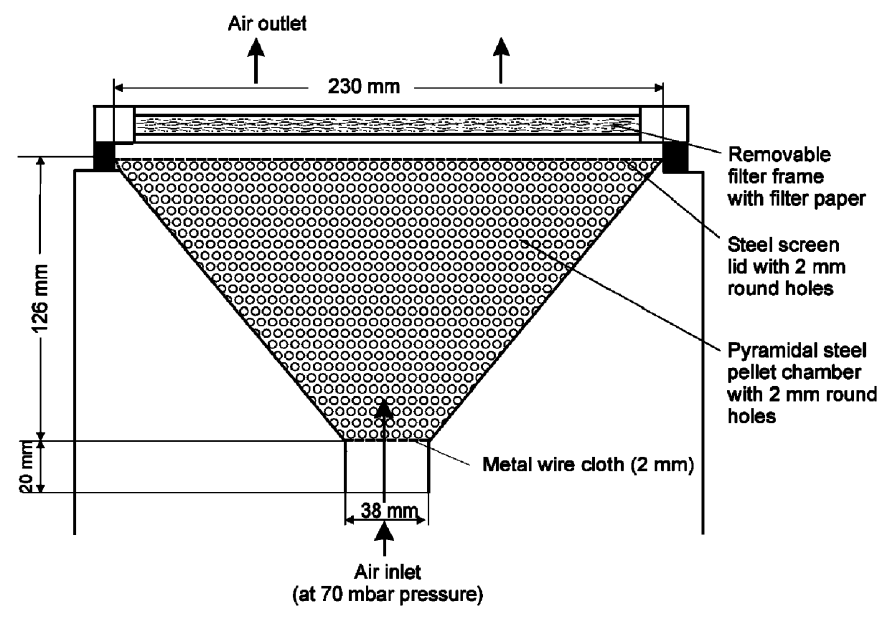

Fig. 3. ÖNORM M 7135 apparatus for durability testing of pellets.

testing, the 105 rotations period was chosen. Fines were separated by using a $3.15 \mathrm{~mm}$ round hole sieve [8]. The number of replications was set to 5 .

\subsubsection{Method testing}

The tests performed on pellets were divided in two tests series related to two different pellet selections (Table 2).

2.3.3.1. First test series. The aim of the first test series was to compare results gained by the three selected methods. Trials were performed on the pellets of the first selection (Selection 1, Table 2). Two laboratories tested the tumbler described in ASAE S269.4 (in three replications); the Lignotester according to ÖNORM M7135 (in 20 replications) was tested by five laboratories and one laboratory used the briquette DU drum (five replications) for determinations on pellets. Besides the differences among the tested devices, the analysis also focussed on differences between pellet subgroups (agricultural residues pellets, 6 and $8 \mathrm{~mm}$ diameter wood pellets, high-DU pellets). The high-DU pellets correspond to the highest DU class (DU over 97.5\%) according to CEN/TS 14961 [10]. Additionally, the measured DU values were compared to the pellet particle densities.

2.3.3.2. Second test series. The second test series was based on the results of the first series; an international round robin test was organised with four participating laboratories measuring 11 pellet types (Selection 2, Table 2). The numbers of replications were fixed to 5 and 10, respectively, for the ASAE S 269.4 and the ÖNORM M7135 standards. This round robin focussed on the DU repeatability and reproducibility limits, and on the relation between the results of these two standard methods.

\subsection{Repeatability, reproducibility and number of replications}

The absolute and relative repeatability and reproducibility limits (when applicable) of the tested methods were calculated following ISO 5725.1 and 2 [11]. The required minimum number of replications to achieve a given accuracy level is calculated following a common statistical calculation procedure according to Dagnelie, 1975, vol. 2, p. 30 [12], the considered Type I and Type II errors are, respectively, $\alpha=0.05$ and $\beta=0.5$.

\subsection{Particle density}

Particle density is the ratio of the sample mass and its volume including pore volume. The volume of the selected pellets and briquettes was estimated using the buoyancy method in liquid. This method has been shown to have a low variability $[13,14]$. The method is based on the Archimedes principle; the pellet sample is weighed in air and in a liquid. By knowing the liquid density the volume of the sample can be calculated. For the determination of pellets, a commercially available density determination kit was applied while for briquette measurements a setup with a below-balance weighing hanger was used.

The pellet samples had a mass of 5-8g, the briquettes were prepared to have a length equal to two times the diameter.

For pellet testing a wetting agent was added to the water in order to avoid bubbles formation and to allow the liquid to fill voids and pores that communicate with the surface of the pellets ( $t$-Octylphenoxypolyethoxyethanol; polyethylene glycol tert-octylphenyl ether-CAS number: 9002-931 - trade mark Triton X-100) at a concentration of $1.5 \mathrm{~g} / 1$, which leads to a liquid density of $0.996 \mathrm{~kg} / 1$. In laboratory conditions, the effect of the temperature on the liquid density was neglected.

Due to the fast disintegration of the briquette samples in the liquid when using wetting agent, the particle density of the selected briquettes was measured in pure water.

\section{Results and discussion}

Fig. 4 shows the results (mean values of all laboratories and standard deviations) of the DU measurements, for the

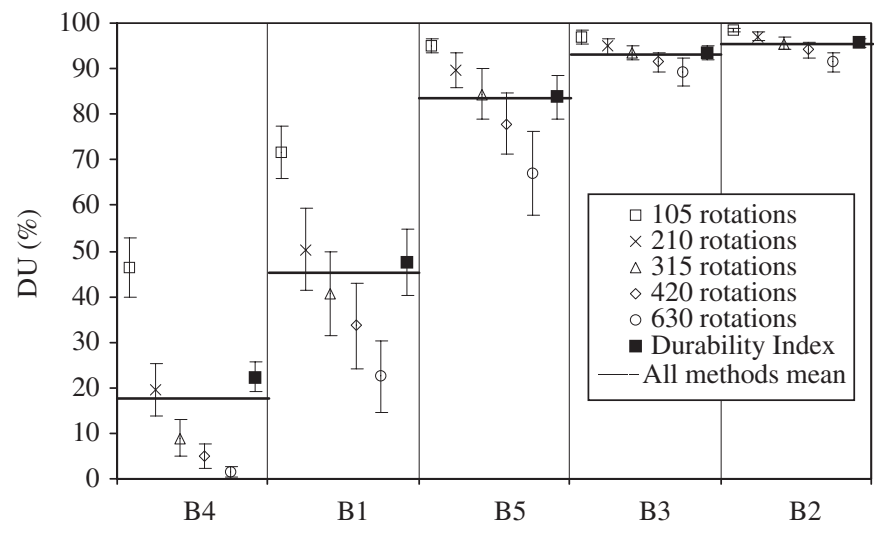

Fig. 4. Durability (DU) of five briquette types determined by five periods of drum rotations and by the durability index (mean values plus/minus standard deviations of five laboratories). 
five briquette types tested during the round robin test. The standard deviation includes the variation within individual laboratories and between laboratories. As expected, the DU values decreased with an increasing number of rotations. The figure also shows that the individual briquette type influenced the variability (standard deviation) of the DU measurements. The standard deviation of the measurements increased with a larger number of drum rotations (except B4, for which destruction of the sample was observed).

The DU index gives a value close to the mean value calculated for all tested rotation numbers. Nevertheless, the variability of the DU index is higher than for the 105 rotation method, except for the briquette with the lowest DU (B4).

Table 3 shows, for each tested method, the absolute $(r)$ and the relative $(r \%)$ values of the repeatability limits (mean value of the laboratories involved in the round robin), as well as the values of the reproducibility limits (absolute, $R$, and relative, $R \%$ ). The required minimum numbers of replications in order to achieve a given accuracy level $(2 \%, 5 \%$ and $10 \%)$ are also indicated.

For all tested methods the repeatability and reproducibility limits are high, when all briquette types are considered. Nevertheless, the 105 rotations period leads to the lowest relative repeatability value $(15.0 \%)$ and the lowest relative reproducibility limit $(40.9 \%)$. The comparatively low repeatability limit of the 105 rotations test period leads to a lower required number of replications to achieve a given accuracy level. For example, to secure an accuracy level of $10 \%, 39$ replications shall be conducted, while a number of 966 replications should be necessary for the 630 rotations method.

From a practical point of view, it seems that an accuracy level better than $10 \%$ can hardly be achieved for the DU estimation of briquettes by the tested trial setup. Indeed, even with the 105 rotations method, the time necessary to perform one single determination is relatively long (a 105 rotations test needs $5 \mathrm{~min}$ ). Improvement of the method should be tested; in particular, higher rotation speeds than the $21 \mathrm{rpm}$ applied here could shorten the required rotation times. Moreover, the high variability might be enhanced by larger individual sample volumes.

Nevertheless, for briquettes of DU above $90 \%$, the accuracy of the method is improved. Table 4 shows, for the 105 rotation period, that absolute and relative repeatability limits of briquettes having a DU of $90 \%$ and above, are both below 5\%, while they are higher for DUs below $90 \%$. The same observation was made for the absolute and relative reproducibility limits, which are also improved for briquettes of a DU of $90 \%$ and above. Table 4 also shows that, for DUs of $90 \%$ and above, only one replication is needed to achieve 5\% accuracy, while five replications secure an accuracy of $2 \%$.

For the selected pellets (Selection 1, Table 2) the first test series had a DU range from $93.6 \%$ to $99.4 \%$, when the

Table 3

Briquettes durability testing: relative and absolute repeatability ( $r$ and $r \%$, mean of five laboratories) and reproducibility limits $(R$ and $R \%$ ); minimum required number of replications to achieve a given accuracy level $(N)$ for the given numbers of rotations and the durability index

\begin{tabular}{|c|c|c|c|c|c|c|c|}
\hline \multirow[t]{2}{*}{ Method } & \multirow[t]{2}{*}{$r^{\mathrm{a}}$} & \multirow[t]{2}{*}{$r \%{ }^{\mathrm{b}}$} & \multirow[t]{2}{*}{$R^{\mathrm{a}}$} & \multirow[t]{2}{*}{$R \%{ }^{\mathrm{b}}$} & \multicolumn{3}{|l|}{$N$} \\
\hline & & & & & $2 \%$ & $5 \%$ & $10 \%$ \\
\hline 105 rotations & 12.3 & 15.0 & 33.4 & 40.9 & 974 & 156 & 39 \\
\hline 210 rotations & 15.4 & 21.9 & 43.9 & 62.6 & 6611 & 1058 & 264 \\
\hline 315 rotations & 15.9 & 24.6 & 40.5 & 62.7 & 14548 & 2328 & 582 \\
\hline 420 rotations & 16.8 & 27.9 & 38.4 & 63.5 & 18494 & 2959 & 740 \\
\hline 630 rotations & 18.3 & 33.6 & 37.1 & 68.2 & 24148 & 3864 & 966 \\
\hline Durability Index & 12.9 & 18.8 & 33.8 & 49.3 & 2114 & 338 & 85 \\
\hline
\end{tabular}

\footnotetext{
${ }^{\mathrm{a}}$ Absolute values $(\%)$.

${ }^{\mathrm{b}}$ Relative values ( $\%$ of DU).
}

Table 4

Briquettes durability testing: relative and absolute repeatability ( $r$ and $r \%$, mean of five laboratories) and reproducibility limits ( $R$ and $R \%$ ); minimum required number of replications to achieve a given accuracy level $(N)$ for 105 rotations and briquettes above and below durability of $90 \%$

\begin{tabular}{|c|c|c|c|c|c|c|c|}
\hline \multirow[t]{3}{*}{ Briquette durability } & \multicolumn{7}{|c|}{105 rotations method } \\
\hline & \multirow[t]{2}{*}{$r^{\mathrm{a}}$} & \multirow[t]{2}{*}{$r \%{ }^{\mathrm{b}}$} & \multirow[t]{2}{*}{$R^{\mathrm{a}}$} & \multirow[t]{2}{*}{$R \%{ }^{\mathrm{b}}$} & \multicolumn{3}{|l|}{$N$} \\
\hline & & & & & $2 \%$ & $5 \%$ & $10 \%$ \\
\hline $\mathrm{DU} \geqslant 90 \%$ & 18.8 & 31.8 & 52.6 & 89.2 & 974 & 156 & 39 \\
\hline $\mathrm{DU}<90 \%$ & 3.9 & 4.1 & 4.6 & 4.7 & 5 & 1 & 1 \\
\hline
\end{tabular}

\footnotetext{
${ }^{\mathrm{a}}$ Absolute values (\%).

${ }^{\mathrm{b}}$ Relative values ( $\%$ of DU).
} 
tumbler according to ASAE S269.4 was applied. The same pellets determined by the Lignotester following ÖNORM M7135 showed a DU range from $91.2 \%$ to $99.3 \%$. Tests performed using the briquette drum lead to smaller result range, from $97.6 \%$ to $99.8 \%$.

Fig. 5 shows the mean values and the standard deviations for all laboratories of the DU results on 15 pellet types and for the three tested methods. The standard deviation includes the variation within the individual laboratories and between the laboratories.

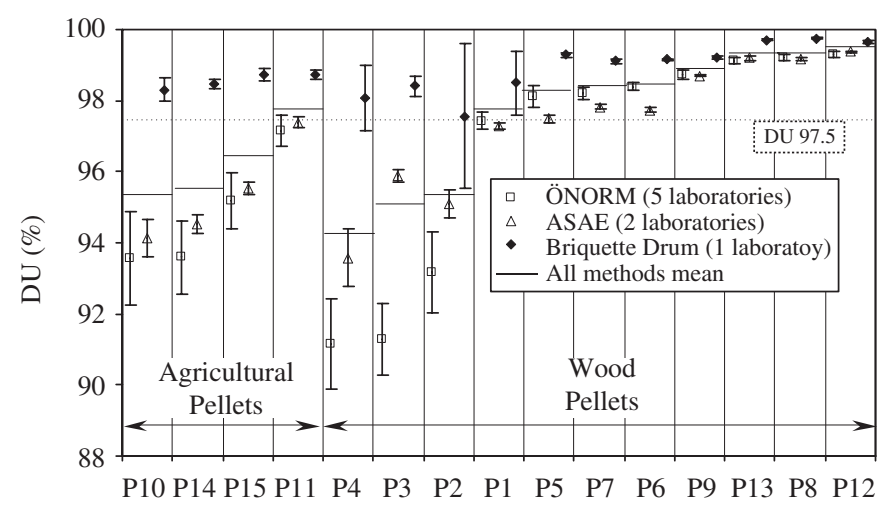

Fig. 5. Durability (DU) of 15 pellets determined by three different methods (mean values plus/minus standard deviations of involved laboratories).
For both wood and agricultural residues pellets, the differences between results from ASAE and ÖNORM standards are larger for pellets below DU $97.5 \%$. Furthermore, for this pellet group the Lignotester of the ÖNORM standard leads to lower DU values compared to the tumbler according to ASAE standard. For high-DU pellets (DU $97.5 \%$ or more), values gained by ASAE and ÖNORM are more similar, while the tumbler according to ASAE standard seems to measure slightly lower DU values. A test of variance equality performed on the three tested methods (Bartlett test, significance level $\alpha=0.05$ ) confirms that the individual pellet type highly influences the variability of the measurements. Moreover, the standard deviation observation shows that the DU factor level influences the variability: the lower the pellets DU is, the higher the variability is (Fig. 5). However, the comparison of the coefficient of variation ( $T$-test, significance level $\alpha=0.05$ ) indicates that ASAE standard systematically leads to lower variability, compared to ÖNORM.

The variability of the briquette tester (only tested at one laboratory) is generally low compared to the two other methods. Nevertheless, the DU values of the different pellet types are relatively close together, thus a pellets differentiation or a classification according to this method can hardly be realised.

Table 5 shows, for ASAE and ÖNORM methods, the mean values of absolute $(r)$ and relative $(r \%)$ repeatability limits (for laboratories involved in the method testing) and

Table 5

Pellets durability testing: relative and absolute repeatability and reproducibility limits for the tested methods

\begin{tabular}{|c|c|c|c|c|c|c|c|c|}
\hline \multirow[t]{2}{*}{ Method } & \multirow[t]{2}{*}{ Involved labs } & \multirow[t]{2}{*}{$r^{\mathrm{a}}$} & \multirow[t]{2}{*}{$r \% \mathrm{~b}$} & \multirow[t]{2}{*}{$R^{\mathrm{a}}$} & \multirow[t]{2}{*}{$R \%{ }^{\mathrm{b}}$} & \multicolumn{3}{|l|}{$N$} \\
\hline & & & & & & $0.5 \%$ & $1 \%$ & $2 \%$ \\
\hline \multicolumn{9}{|l|}{ All pellets } \\
\hline ASAE & 2 & 0.9 & 0.9 & 1.4 & 1.5 & 24 & 6 & 1 \\
\hline Önorm & 5 & 2.1 & 2.2 & 3.8 & 4.0 & 83 & 22 & 5 \\
\hline Briquette drum & 1 & 1.8 & 1.8 & & & 67 & 17 & 4 \\
\hline \multicolumn{9}{|l|}{$6 \mathrm{~mm}$ diameter } \\
\hline ASAE & 2 & 1.0 & 1.0 & 2.4 & 2.4 & 24 & 6 & 1 \\
\hline Önorm & 5 & 2.1 & 2.2 & 3.8 & 4.0 & 83 & 22 & 5 \\
\hline Briquette drum & 1 & 2.4 & 2.4 & & & 67 & 17 & 4 \\
\hline \multicolumn{9}{|l|}{$8 \mathrm{~mm}$ diameter } \\
\hline ASAE & 2 & 0.2 & 0.3 & 1.4 & 1.4 & 1 & 1 & 1 \\
\hline Önorm & 5 & 0.6 & 0.6 & 2.9 & 3.0 & 3 & 1 & 1 \\
\hline Briquette drum & 1 & 0.2 & 0.2 & & & 1 & 1 & 1 \\
\hline \multicolumn{9}{|c|}{ Agricultural residues pellets } \\
\hline ASAE & 2 & 0.9 & 1.0 & 2.1 & 2.2 & 7 & 3 & 1 \\
\hline Önorm & 5 & 2.8 & 2.9 & 7.1 & 7.5 & 49 & 12 & 3 \\
\hline Briquette drum & 1 & 0.6 & 0.6 & & & 2 & 1 & 1 \\
\hline \multicolumn{9}{|c|}{ Wood pellets $D U>97.5$} \\
\hline ASAE & 2 & 0.1 & 0.1 & 0.4 & 0.4 & 1 & 1 & 1 \\
\hline Önorm & 5 & 0.3 & 0.3 & 1.0 & 1.0 & 3 & 1 & 1 \\
\hline Briquette drum & 1 & 0.1 & 0.1 & & & 1 & 1 & 1 \\
\hline
\end{tabular}

The minimum required number of replications for a given accuracy level are also given.

${ }^{\mathrm{a}}$ Absolute values $(\%)$.

${ }^{\mathrm{b}}$ Relative values ( $\%$ of DU). 
the mean values of absolute $(R)$ and relative $(R \%)$ reproducibility limits. The table also indicates the number of replication needed to achieve a given accuracy level $(0.5 \%, 1 \%, 2 \%)$. These parameters are calculated for 6 and $8 \mathrm{~mm}$ wood pellets, agricultural residues pellets, and for all pellets together. Additionally, these values are given for pellets having a DU of more than $97.5 \%$ (according to ASAE S 269.4).

The absolute and relative repeatability values are, regarding all pellets, 0.9 for the ASAE standard and 1.8 for the briquette tester. For the ÖNORM standard " $r$ " is 2.1 and " $r \%$ " is 2.2. Again the pellets DU influences the repeatability values. The lowest repeatability limits (both absolute and relative) were observed for high-DU pellets.

For the whole pellets selection, the reproducibility values (absolute and relative) are: 1.4 and 1.5 ( $R$ and $R \%$, respectively) for the ASAE standard. The ÖNORM leads to higher variability between laboratories; the $R$ value is 3.8 and the $\mathrm{R} \%$ value is 4.0. As for repeatability, the tested fuels influence this parameter.

For all investigated subgroups of pellets, the ÖNORM standard leads to higher repeatability and reproducibility values (higher variability) than the ones obtained by following ASAE standard.

This is also reflected by the required minimum number of replications to achieve a given accuracy level (Table 5). The low result variability of the ASAE standard leads to a smaller amount of required replications. For example, to secure an accuracy level of $1 \%$, only six replications are needed when all selected pellets are regarded, while 22 are required for the ÖNORM standard. Table 5 also reveals that the demanded five replications of the ÖNORM standard lead to an accuracy level of $2 \%$.

It also appears that accuracy levels below $0.5 \%$ can only be achieved for high-density pellets, at least with practicable numbers of replications. Indeed, even using the ASAE method 24 replications are needed considering all pellet types.

Nevertheless, the data presented here were calculated for a great variation of pellet types. For other pellets the required number of replications can be far smaller, e.g. only six replications are required to obtain a precision of $0.1 \%$, when ASAE method is used on pellets having a DU above $97.5 \%$.

The test series on the second pellets selection (Selection 2, Table 2) leads to DU ranges from $95.6 \%$ to $99.4 \%$, estimated by the tumbler following ASAE S269.4. The same pellets measured by the Lignotester according to ÖNORM lead to DU values between $92.7 \%$ and $99.4 \%$. Fig. 6 shows the mean values for DU and the standard deviation for 11 pellet types tested by all laboratories participating in the round robin. It appears that nine of the selected pellets have a DU (estimated by ASAE S269.4) above $97.5 \%$ and thus belong to the highest pellets quality class according to [12].

As expected from the first test series, an ANOVA (significance level $\alpha=0.05$ ) confirms that results gained by

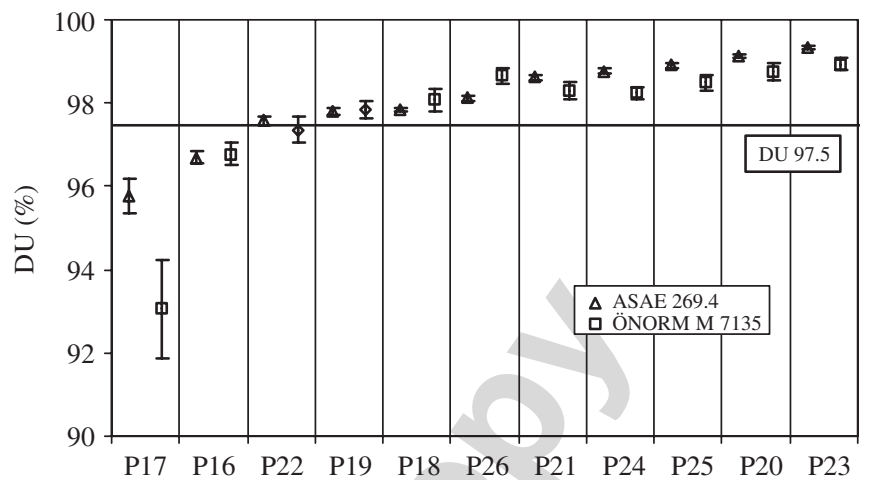

Fig. 6. Durability (DU) of 11 pellets estimated by ASAE S269.4 and ÖNORM M 7135 (mean value and standard deviation of four laboratories).

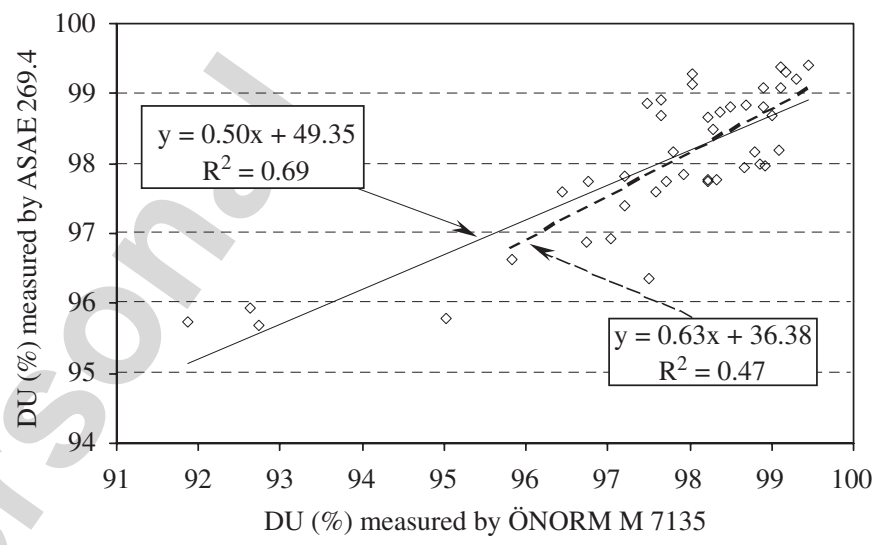

Fig. 7. Relation between ÖNORM M 7135 and ASAE S269.4 results for durability (DU) of pellets.

ASAE and ÖNORM are significantly different. A $T$-test (significance level $\alpha=0.05$ ) comparing coefficient of variation of the two methods indicates the higher variability of the ÖNORM measurements.

A linear regression analysis (significance level $\alpha=0.05$ ) was conducted with results given by the tumbler according to ASAE and the Lignotester according to ÖNORM (Fig. 7). When all selected pellets are considered, the coefficient of determination $R^{2}$ for the regression line is 0.69 . When only pellets with a DU of more than $96 \%$ are regarded, the coefficient of determination is lower $\left(R^{2}=0.47\right)$. The low coefficients of determination indicate that it is hazardous to extrapolate results from one method to the other.

The calculation of the repeatability and the reproducibility limits of the ASAE and ÖNORM methods confirm the results obtained in the first test series (Table 6). Also, here both parameters are lower for the ASAE S269.4 than for the ÖNORM M 7135.

Fig. 8 shows DU values of 15 tested pellets (Selection 1, Table 2) which were determined by the ASAE tumbler, they are compared to their respective particle densities. It appears that no clear relation can be drawn between these two parameters. A linear regression analysis (significance 
Table 6

Pellets durability testing absolute and relative repeatability and reproducibility

\begin{tabular}{lllll}
\hline Method & $r^{\mathrm{a}}$ & $r^{0}{ }^{\mathrm{b}}$ & $R^{\mathrm{a}}$ & $R^{\mathrm{b}}{ }^{\mathrm{b}}$ \\
\hline ASAE & 0.6 & 0.6 & 0.7 & 0.7 \\
ÖNORM & 1.0 & 1.1 & 3.0 & 3.0 \\
\hline
\end{tabular}

${ }^{\mathrm{a}}$ Absolute values.

${ }^{\mathrm{b}}$ Relative values.

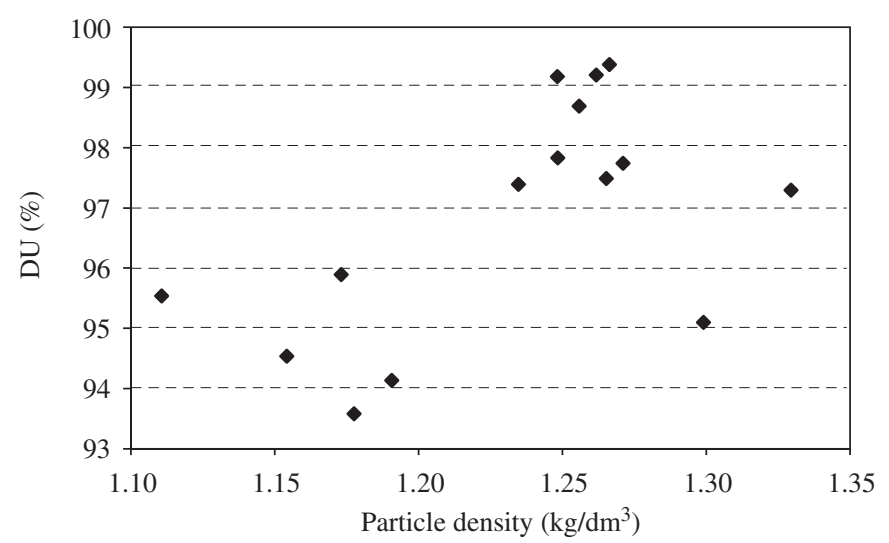

Fig. 8. Relation between durability (ASAE S269.4) and particle density for the 15 tested pellets $\left(R^{2}=0.33\right)$.

level $\alpha=0.05$ ) revealed a coefficient of determination, $R^{2}$, of 0.33 . In contradiction to the statement of several pellet producers, this confirms observations made by Obernberger and Thek [4]. For pellets made from different raw material, produced by different equipment and under variable conditions, there is no relation between DU and particle density of pellets. The correlation between briquette DU and particle density has also been investigated, for the five selected briquette types. But, also for briquettes, no relation between these two properties was found.

\section{Conclusions}

The results from the briquette testing support the conclusion that briquette DU is best determined by tumbling in a drum for 105 rotations. For this treatment, the lowest repeatability and reproducibility limits were given. Nevertheless, the briquette DU testing is associated with a relatively high variation of the results, particularly when considering the full range of possible briquette types. With the equipment applied here, accuracies below 10\% can hardly be achieved in practice. However, for briquettes having a DU of $90 \%$ and higher, an accuracy level of $2 \%$ can be achieved by five replications. The applicability for proving any conformity with relatively high briquette quality is given by the method investigated here.

For pellet testing, the tumbling device described by the ASAE S 269.4 gives the most repeatable and reproducible results. Moreover, this method requires the least number of replications to achieve a given accuracy level, while measurements with the pneumatic device following ÖNORM M 7135 imply a higher number of replications. In practice, an accuracy level of $0.5 \%$ can be reached when the tumbling device according to ASAE is applied, this is particularly true for high DU pellets.

The variation of DU measurements for briquettes and pellets is highly influenced by the fuel type and the fuel properties. For most individual fuel types the required minimum number of replications to achieve a given accuracy level is far smaller than for a collection of pellets or briquettes.

There is no clear correlation between the DU results of pellets measured by the tumbling device and those given by the Lignotester. Generally comparisons between the two methods are thus not advisable. In the same way, useful correlations between DU and particle density could not be observed, neither for briquettes nor for pellets.

\section{Acknowledgements}

The research was conducted within the European project "Pre-normative work on sampling and testing of solid biofuels for the development of quality assurance systems" (BioNorm) ENK6-CT-2001-00556. The authors would like to express their gratitude to the following laboratories and persons who have participated in the round robin tests:

Bundesanstalt für Landtechnik (BLT), Wieselburg, Austria (J. Rathbauer).

Centro de investigaciones energéticas, Medioambientales y tecnologicas (CIEMAT), Madrid, Spain (Juan Carrasco and Miguel Fernandez).

Holzforschung Austria (HFA), Wien, Austria (Michael Golser).

Work Efficiency Instistute (TTS), Rajamäki, Finland (Seppo Tuomi).

\section{References}

[1] Vinterbäck J. Pellets 2002: the first conference on pellets. Biomass \& Bioenergy 2004;27:513-20.

[2] Lehtikangas P. Storage effects on pelletised sawdust, logging residues and bark. Biomass and Bioenergy 2000;19:287-93.

[3] Technical Specification CEN/TS14588: solid biofuels-terminology, definitions and descriptions.

[4] Obernberger I, Thek G. Physical characterisation and chemical composition of densified biomass fuels with regards to their combustion behaviour. Biomass and Bioenergy 2004;27:653-69.

[5] Lequeux P, Carré J, Hébert J, Lacrosse L, Schenkel Y. Energie et biomasse, la densification, Les presses agronomiques de Gembloux, Belgium, 1990, 188pp.

[6] ISO 3310-1 Tests sieves - technical requirement and testing - Part 1: test sieves of metal wire cloth.

[7] ASAE S269.4 Dec 96, Cubes, pellets and crumbles-definitions and methods for determining density, durability and moisture content. 
[8] ISO 3310-2 Test sieves - technical requirements and testing-Part 2 : test sieves of perforated metal plate.

[9] ÖNORM M 7135, Preßlinge aus naturbelassenem Holz und naturbelassender Rinde-Pellets und Briketts -Anforderungen und Prüfbestimmungen.

[10] Technical Specification CEN/TS 14961: solid biofuel-fuel specification and classes.

[11] ISO 5725.1-ISO 5725.2, Accuracy (trueness and precision) of measurement methods and results-Part 1: general principles and definitions, Part 2: basic method for the determination of repeatability and reproducibility of a standard measurement method, 1994.
[12] Dagnelie P. Théorie et méthodes statistiques volume 1 et 2 , § 10.2.4. Presses agronomiques de Gembloux, 1975. (Statistics, theory and methods - in French).

[13] Rabier F, Temmerman M, Jensen PD, Hartmann H, Böhm T, Rathbauer J, Carrasco J, Fernandez M. Particle density of pellets and briquettes, In: Proceedings of the international conference on "Standardisation of solid biofuels", 06-07/10/2004, Leipzig, Germany, 2004. p. 153-65.

[14] Böhm T, Hartmann H. Measuring particle density of wood pellets. In: Proceedings of the second world conference and technology exhibition on biomass for energy, industry and climate protection, 1014/05/2004, Rome, Italy, 2004. p. 683-86. 